\title{
Mechanical properties of $\mathrm{Cu}_{6} \mathrm{PS}_{5} \mathrm{I}$ superionic crystals and thin films
}

\author{
V.V. Bilanych ${ }^{1}$, A.V. Bendak ${ }^{1}$, K.V. Skubenych ${ }^{1}$, F. Lofaj $^{2}$, I.P. Studenyak ${ }^{1}$, V.S. Bilanych ${ }^{1}$, V.M. Rizak ${ }^{1}$ \\ ${ }^{1}$ Uzhhorod National University, 46, Pidhirna Str., 88000 Uzhhorod, Ukraine \\ ${ }^{2}$ Institute of Materials Research of SAS, 47 Watsonova Str., 04001 Kosice, Slovakia \\ *Corresponding author phone: +380997973016 \\ E-mail: studenyak@dr.com
}

\begin{abstract}
The hardness and Young's modulus dependences on the instrumented indentation depth profiles in $\mathrm{Cu}_{6} \mathrm{PS}_{5} \mathrm{I}$ single crystals and $\mathrm{Cu}_{6} \mathrm{PS}_{5} \mathrm{I}$-based thin films were investigated. The measurements of mechanical parameters were performed at the room temperature by instrumented indentation in the continuous stiffness measurement mode with harmonic modulation of load during its linear increase. The variations of the hardness and Young's modulus in $\mathrm{Cu}_{6} \mathrm{PS}_{5} \mathrm{I}$ single crystals were interpreted in the framework of deformation gradient model. The decrease of micro-hardness in $\mathrm{Cu}_{6} \mathrm{PS}_{5} \mathrm{I}$-based thin film observed with copper content increase was explained by formation of conductive clusters and dendrites.
\end{abstract}

Keywords: superionic crystals, thin films, hardness, Young's modulus, nano- and microindentation.

doi: https://doi.org/10.15407/spqeo22.01.47

PACS 71.70.Gm, 61.43.Fs

Manuscript received 01.02.19; revised version received 18.02.19; accepted for publication 20.02.19; published online 30.03.19.

\section{Introduction}

$\mathrm{Cu}_{6} \mathrm{PS}_{5} \mathrm{I}$ compound belongs to the superionic conductors with argyrodite structure [1]. It crystallizes in the cubic crystal system (space group $F \overline{4} 3 m$ ) at room temperature. At low temperatures, the $\mathrm{Cu}_{6} \mathrm{PS}_{5} \mathrm{I}$ crystal undergoes two phase transitions (PTs), one of them being a first-order superionic and ferroelastic PT at $T_{\mathrm{I}}=144 \ldots 169 \mathrm{~K}$, the other is second-order structural PT at $T_{\mathrm{II}}=(269 \pm 2) \mathrm{K}[2,3]$. Gagor et al. [3] noted that at $T_{\mathrm{I}}<T<T_{\text {II }}$ the $\mathrm{Cu}_{6} \mathrm{PS}_{5} \mathrm{I}$ crystals belong to a cubic system (space group $F \overline{4} 3 c$ ), while at $T<T_{\mathrm{I}}$ it belongs to the monoclinic system (space group $C c$ ). Electrical, acoustical and optical properties of $\mathrm{Cu}_{6} \mathrm{PS}_{5} \mathrm{I}$ crystals as well as the influence of structural and compositional disordering onto physical properties of $\mathrm{Cu}_{6} \mathrm{PS}_{5} \mathrm{I}$-type superionic conductors were studied in numerous works [4-9]. Due to the high electrical conductivity, they are promising materials for wide application as the solid electrolytes, supercapacitors, ion-selective membranes, and others electrochemical devices. Moreover, they are also interesting materials for the fundamental studies of the order-disorder processes as well as of the structural relaxation ones.
Information about physical parameters in submicron regions is important for the development of nanocomposites and thin layers based on these superionic materials. It is well known that if the volume of solidstate sensing decreases $(<100 \mathrm{~nm})$, the physical parameters will approach to theoretically possible values [10]. Instrumented indentation belongs to few effective techniques that are able to detect mechanical properties in this size range [11]. However, instrumented indentation has not been used for the study of $\mathrm{Cu}_{6} \mathrm{PS}_{5} \mathrm{I}$ single crystals and $\mathrm{Cu}_{6} \mathrm{PS}_{5} \mathrm{I}$-based thin films up to now.

Therefore, the aim of this work was to investigate the hardness and Young's modulus dependences on the penetration depth in $\mathrm{Cu}_{6} \mathrm{PS}_{5} \mathrm{I}$ single crystals and $\mathrm{Cu}_{6} \mathrm{PS}_{5} \mathrm{I}-$ based thin films as a function of their chemical composition by using nanoindentation.

\section{Material and methods}

The nanoindentation studies include measurements on single crystals and thin films. Single crystals of $\mathrm{Cu}_{6} \mathrm{PS}_{5} \mathrm{I}$ with the size of $5 \times 5 \times 3 \mathrm{~mm}$ were obtained using the chemical transport evaporation method. $\mathrm{Cu}_{6} \mathrm{PS}_{5} \mathrm{I}$-based thin films were deposited onto silicate glass substrates with non-reactive radiofrequency magnetron sputtering. 
To obtain the thin films with different copper content, a system with the glass substrate moving with respect to pure copper and $\mathrm{Cu}_{6} \mathrm{PS}_{5} \mathrm{I}$ compound targets. Thus, the ratio of chemical elements in the coating continuously changed in dependence on the distance from the corresponding targets. The chemical composition of the thin films was determined using energy dispersive X-ray spectroscopy (EDX).

The hardness $H$ and indentation modulus $E$ measurements were performed using G200 (Agilent, USA) nanoindenter at room temperature by using the continuous stiffness measurement (CSM) mode in the load control regime [11]. The load $F_{m}$ on indenter linearly increased up to $100 \mathrm{mN}$ at a rate of $10 \mathrm{mN} / \mathrm{s}$, and simultaneously the harmonic force $F_{1}$ with $1 \mathrm{mN}$ amplitude and frequency $f=45 \mathrm{~Hz}$ was applied to the indenter. As a result, the time dependence of the resulting load on the indenter can be described by the equation:

$F=\frac{d F}{d t} \cdot t+F_{1} \cdot \sin (\omega t)$

where $\frac{d F}{d t}=10 \mathrm{mN} / \mathrm{s}, \omega=2 \pi f, F_{1}=1 \mathrm{mN}$.

Microhardness measurements in $\mathrm{Cu}_{6} \mathrm{PS}_{5} \mathrm{I}$-based thin films with different copper content were performed using PMT-3 microindenter (with the Vickers indenter) at room temperature.

\section{Results and discussion}

\subsection{Nanoindentation in single crystals}

Fig. 1 shows the typical load - indentation depth " $P-h$ " curve in $\mathrm{Cu}_{6} \mathrm{PS}_{5} \mathrm{I}$ single crystal. The loading rate was chosen in such a manner that the time of loading to the maximum load was $10 \mathrm{~s}$. The dwell time at the maximum load was $10 \mathrm{~s}$ and $100 \mathrm{~s}$. Qualitatively, the " $P-h$ " curves at both dwell times were identical, but the numerical values of $E$ and $H$ for $\mathrm{Cu}_{6} \mathrm{PS}_{5} \mathrm{I}$ crystal were slightly different (see Table). Small decrease in $H$ at longer dwell time indicates larger plastic deformation and simultaneous increase of the indentation depth to more pronounced hardening the crystal structure under the indenter.

Fig. 2 shows the indentation modulus $E$ and hardness $H$ depth profiles in $\mathrm{Cu}_{6} \mathrm{PS}_{5} \mathrm{I}$ single crystals.

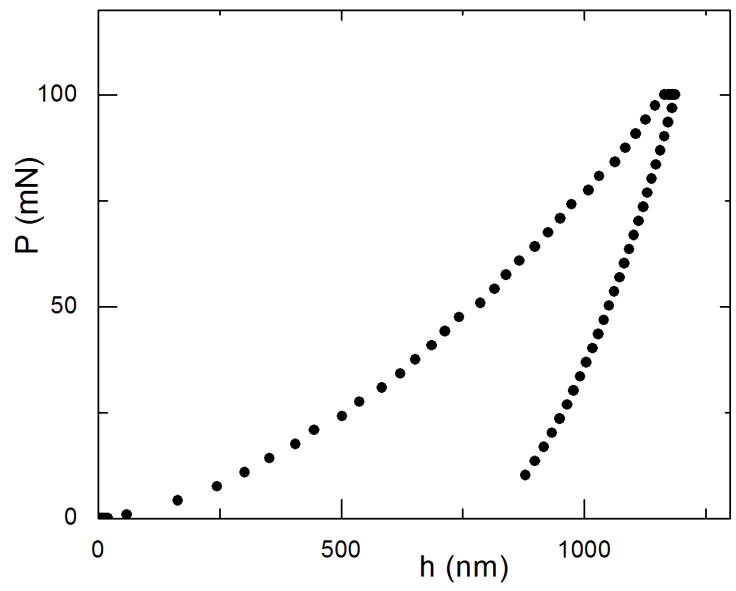

Fig. 1. " $P-h$ " diagram for $\mathrm{Cu}_{6} \mathrm{PS}_{5} \mathrm{I}$ crystal at the load $P=100 \mathrm{mN}$ during $10 \mathrm{~s}$

Each point for $E$ and $H$ in these plots was obtained by averaging the measurements of these parameters at a fixed depth of $h_{i}$ during 20 periods of harmonic load on the indenter [11]. It can be seen that the most significant changes of mechanical properties occurred at the depths below $150 \mathrm{~nm}$. At larger depths, monotonous decrease of $E_{i t}$ and $H_{i t}$ at considerably lower rate was observed.

These changes in hardness are usually called indentation size effects (ISE), and they are related to generation and accumulation of geometrically necessary dislocations and activation of slip systems [12]. It is also known [10] that when the contact region decreases to nanometer range, the values of hardness and elastic modulus increase, and the $\sigma_{m} / E$ ratio approaches theoretical limit of strength of an ideal crystal lattice $\left(\frac{\sigma_{m}}{E} \approx 0.1\right)$, where $\sigma_{m}$ is the maximum theoretical stress the solid can withstand.

At the same time, changes in $E(h)$ and $H(h)$ dependences for $h<150 \mathrm{~nm}$ may be the consequence of a finite radius of the indenter tip, which strongly influences contact area at small depths [21]. Fig. 2 shows continuous decrease of $H_{i t}$ and $E_{i t}$ also at larger depths $h>150 \mathrm{~nm}$ (just the slope is much lower than at smaller depths). It can be assumed that the basic mechanisms of plastic deformation resulting in formation of the indent remained the same as at smaller depths just the contributions of different mechanisms involved in deformation changed with stress (and indentation depth)

Table. Mechanical parameters of $\mathrm{Cu}_{6} \mathrm{PS}_{5} \mathrm{I}$ single crystals and $\mathrm{Cu}_{6.4} \mathrm{P}_{1.2} \mathrm{~S}_{4.6} \mathrm{I}_{0.8}$ thin film as a result of nanoindentation.

\begin{tabular}{|c|c|c|c|c|c|c|c|c|c|}
\hline $\mathrm{N}$ & Material & $\begin{array}{c}H, \mathrm{GPa} \\
10 \mathrm{~s}\end{array}$ & $\begin{array}{c}E, \mathrm{GPa} \\
10 \mathrm{~s}\end{array}$ & $\begin{array}{c}H, \mathrm{GPa} \\
100 \mathrm{~s}\end{array}$ & $\begin{array}{c}E, \mathrm{GPa} \\
100 \mathrm{~s}\end{array}$ & $\begin{array}{c}H, \mathrm{GPa} \\
h=250 \mathrm{~nm}\end{array}$ & $\begin{array}{c}E, \mathrm{GPa} \\
h=250 \mathrm{~nm}\end{array}$ & $\begin{array}{c}H_{\max }, \\
\mathrm{GPa}\end{array}$ & $\begin{array}{c}h_{\max }, \\
\mathrm{nm}\end{array}$ \\
\hline 1 & $\begin{array}{c}\mathrm{Cu}_{6} \mathrm{PS}_{5} \mathrm{I} \\
\text { single crystal }\end{array}$ & 3.3 & 69.9 & 3.2 & 73.9 & 4.4 & 79.6 & 7.1 & 95 \\
\hline 2 & $\begin{array}{c}\mathrm{Cu}_{6.4} \mathrm{P}_{1.2} \mathrm{~S}_{4.6} \mathrm{I}_{0.8} \\
\text { thin film }\end{array}$ & 2.2 & 75.4 & 2.0 & 74.7 & 1.4 & 45.4 & - & - \\
\hline
\end{tabular}




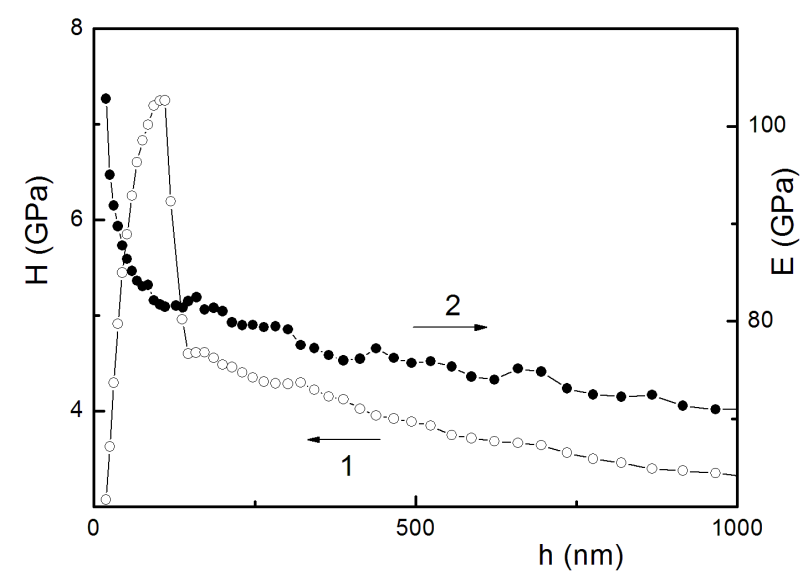

Fig. 2. Dependences of the hardness $H(1)$ and Young's modulus $E(2)$ of $\mathrm{Cu}_{6} \mathrm{PS}_{5} \mathrm{I}$ crystal on the penetration depth of indenter.

increase. The specified mechanisms can be related to formation of various deformation zones in the contact region, to migration of structural defects related changes in the deformation mechanisms of the crystal. In particular, under the sharp indenter in the investigated materials the following areas of deformation such as hydrostatic zone, gradient zone, elastoplastic zone, and elastic zone are observed [13, 14]. The change in the magnitude of these zones and their movement into the depth of the film, to the substrate, leads to a change in the stiffness in the region of the nanocontact and, accordingly, to a change in the values of $E$ and $H$.

When the possible effects of ISE and indenter tip geometry are neglected, a dominance of the elastic mechanism of crystals deformation can be assumed. Then, the dependence $P=f(h)$ can be approximated by the equation [15],

$P=\frac{4}{3} \cdot E_{R} \cdot \sqrt{r h^{3}}$

where $E_{R}$ is the reduced modulus $\frac{1}{E_{R}}=\frac{\left(1-v_{s}^{2}\right)}{E_{s}}+\frac{\left(1-v_{i}^{2}\right)}{E_{i}}$, $r$ - radius at the indenter top, $v$ and $E$ are Poisson's ratio and Young's modulus of the investigated material (s) and indentor (i), respectively. Eq. (2) from the Hertzian theory of mechanical contact of ideal elastic bodies corresponds to a purely elastic deformation [15].

Fig. 3 displays a part of " $P$ - $h$ " curve within the load range $0 . .2 .5 \mu \mathrm{N}$ and the result of their approximation by using Eq. (2). It is visible that the $P(h)$ dependence is well approximated by the Hertzian equation. After neglecting possible indenter radius effects, we can assume that the maximum depth value, for which Eq. (2) is valid, determines the radius of hydrostatic pressure zone.

Fig. 2 shows that the slopes of $E$ and $H$ dependences at $h \geq 150 \mathrm{~nm}$ are reduced as compared to those at smaller depths. This indicates that the main

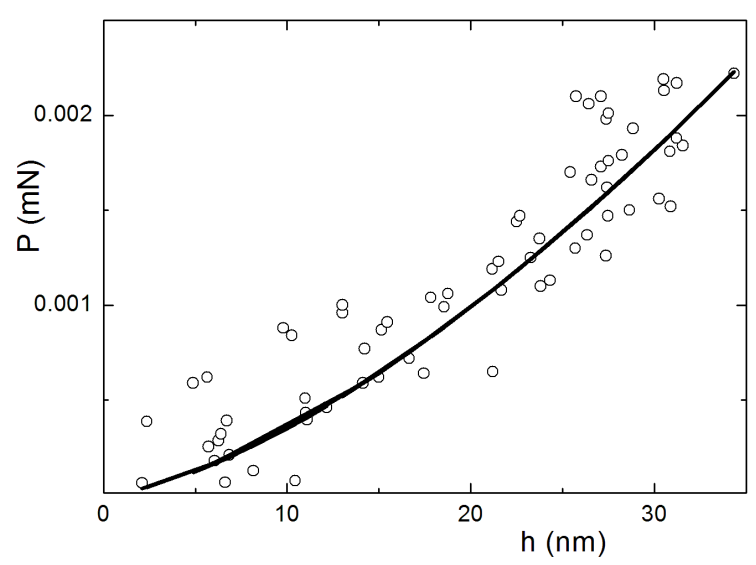

Fig. 3. " $P-h$ " diagram approximation by the Hertzian model for $\mathrm{Cu}_{6} \mathrm{PS}_{5} \mathrm{I}$ in nanoregion.

deformation mechanism at $h \geq 150 \mathrm{~nm}$ gradually stabilizes. It is generally accepted that plastic deformation in the bulk crystalline materials involves the movement of existing defects and formation of new ones, especially dislocations in the contact region [10]. Generation and motion of point defects at the initial stage of plastic deformation of $\mathrm{Cu}_{6} \mathrm{PS}_{5} \mathrm{I}$ crystals may also take place.

The observed hardness dependence in $\mathrm{Cu}_{6} \mathrm{PS}_{5} \mathrm{I}$ crystals with increasing the indentation depth can be interpreted in the framework of the deformation gradient model (MSG) [16-19]. The indentation of crystals would be accompanied by generation of circular loops of geometrically necessary dislocations [16] with Burgers vectors normal to the plane surface of the crystal, according to the strain gradient plasticity theory [18]. Formation of these dislocations leads to the deformation strengthening the crystal. According to this model, the $H(h)$ dependence can be described by the equation [20]:

$\frac{H}{H_{0}}=\sqrt{1+\frac{h^{*}}{h}}$

where $H$ is the hardness for a given depth of imprint $h$, $H_{0}$ - hardness in the limit of infinite depth (hardness in the absence of strain gradient effects [17]) and $h^{*}-$ characteristic length that depends on the indenter shape, the shear modulus and $H$.

According to Eq. (3), $H^{2}$ should be linearly dependent on $h^{-1}$. Fig. 4 shows the dependences $H(h)$ in the coordinates " $H^{2}-h^{-1}$ " for $\mathrm{Cu}_{6} \mathrm{PS}_{5} \mathrm{I}$ crystals. The experimental dependence is well approximated by Eq. (3) in the depth range $h \geq 600 \mathrm{~nm}$. Thus, the dislocation mechanism in $\mathrm{Cu}_{6} \mathrm{PS}_{5} \mathrm{I}$ crystals according to the gradient model (MSG) [16-20] can be applied in this depth region. Transformation of Eq. (3) allowed us to obtain the value of $H_{0}=2.4 \mathrm{GPa}$ from the " $H^{2}-h^{-1}$ " dependence. Subsequently, the value of $h^{*}=0.89 \mu \mathrm{m}$ was determined from the slope of this line. In the transient 150 to $600 \mathrm{~nm}$ 


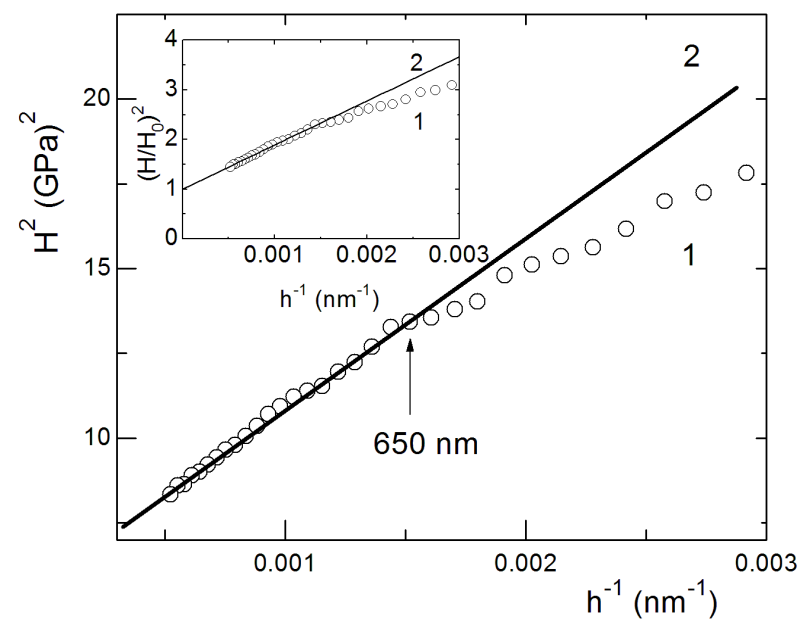

Fig. 4. The size effects approximation of $H(h)$ dependence for the $\mathrm{Cu}_{6} \mathrm{PS}_{5} \mathrm{I}$ crystal in the model of gradient deformations in the micro-region. The inset shows the $H(h)$ dependence of the $\mathrm{Cu}_{6} \mathrm{PS}_{5} \mathrm{I}$ crystal, normalized to $H_{0}$, in the “( $\left(\frac{H^{2}}{H_{0}^{2}}\right)-h^{-1}$ "coordinates $(1-$ experiment, 2 - result of a linear approximation).

region, a mixed mechanism of plastic deformation seems to be valid. Formation of plastic deformation occurs at the expense of both point defects and dislocations movement.

\subsection{Nanoindentation in thin films}

Fig. 5 illustrates the hardness and indentation modulus depth profiles in $\mathrm{Cu}_{6.4} \mathrm{P}_{1.2} \mathrm{~S}_{4.6} \mathrm{I}_{0.8}$ thin film. These profiles differ substantially from the analogous ones in $\mathrm{Cu}_{6} \mathrm{PS}_{5} \mathrm{I}$ single crystals (Fig. 1) because of strong substrate effect. There is a rapid increase of the $H$ and $E$ parameters within the range $h=20 \ldots 150 \mathrm{~nm}$ due to the effects of indenter tip geometry. At $h \geq 150 \mathrm{~nm}$, the slope decreases, and small plateau is observed. It corresponds

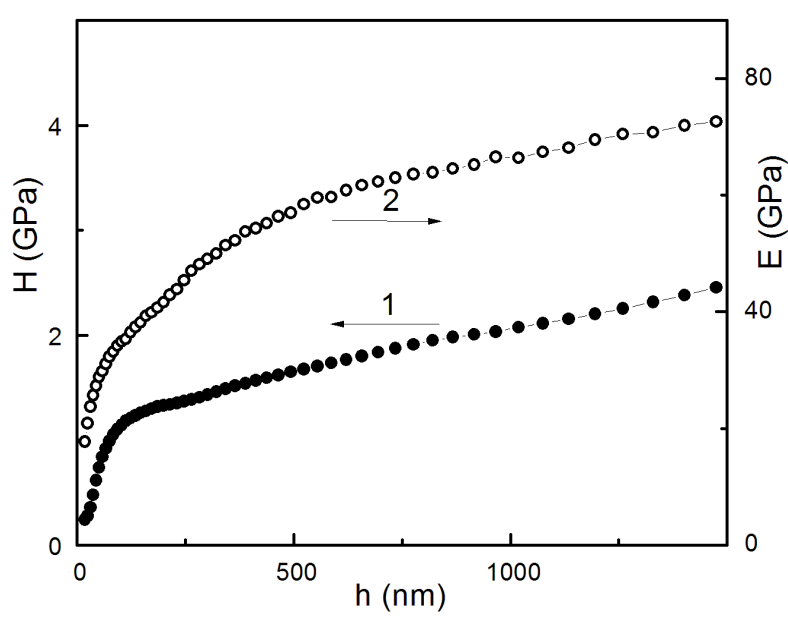

Fig. 5. Dependences of the hardness $H$ (1) and Young's modulus $E$ (2) of $\mathrm{Cu}_{6.4} \mathrm{P}_{1.2} \mathrm{~S}_{4.6} \mathrm{I}_{0.8}$ thin film on penetration depth of indenter. to the hardness of the coating. At larger depths, gradual increase of the hardness and an approach to the hardness of the substrate are observed.

It should be noted that the depth profiles in thin films at $h \leq 100 \mathrm{~nm}$ are strongly influenced by indenter tip radius and tip radius-to-coating thickness ratio [21] and therefore, cannot be used for consideration of physical mechanisms, as it was done in the bulk materials.

The $H(h)$ and $E(h)$ depth profiles at $h>100 \mathrm{~nm}$ can be explained using a model of soft thin film on a rigid substrate [22]. During gradual increase of indenter loading, the elastic (and later plastic) deformation zones under the indenter gradually extend across the thickness of the film and reach the substrate at certain load. Prior to that, the properties of film are mostly measured; after that, the measured $H$ and $E$ values are defined by a gradually changing combination of mechanical properties of the film and substrate. Obviously, the elastic substrate has a greater influence on the contact stiffness related to the elastic deformation than on hardness related to the plastic deformation that occurs later [21-23]. Hardness of the studied $\mathrm{Cu}_{6.4} \mathrm{P}_{1.2} \mathrm{~S}_{4.6} \mathrm{I}_{0.8}$ film is given by the plateau in the depth region $150 \ldots 250 \mathrm{~nm}$ (Fig. 5). Plateau means that $H(h) \approx$ const and the general rule that the obtained value should be from maximum $10 \%$ of the coating thickness is fulfilled. At $h \geq 250 \mathrm{~nm}$, contribution of stiffer and harder substrate results in the increase of measured values.

Fig. 6 illustrates microhardness dependence of $\mathrm{Cu}_{6} \mathrm{PS}_{5} \mathrm{I}$-based thin films on their composition. At 42 at.\% $\mathrm{Cu}$ content, the hardness of the film was around $1.9 \mathrm{GPa}$. $\mathrm{Cu}$ content increase caused rapid decrease of the films hardness to around $0.7 \mathrm{GPa}$. At the same time, the conductivity of these films increased [24, 25]. It is well known that high ionic conductivity of the investigated thin films is caused by formation of conductive channels from dendrites and crystal clusters by spinodal decomposition when the copper content increases [26].

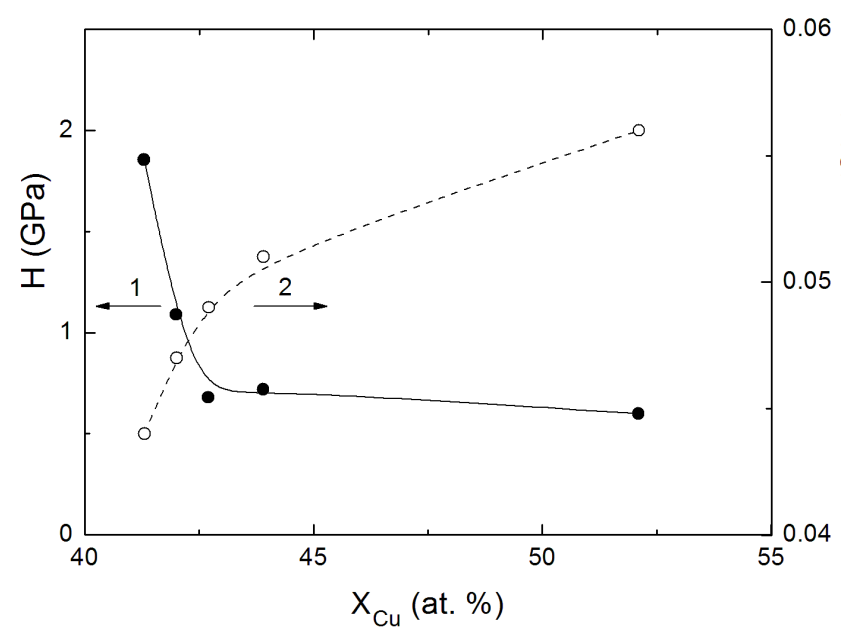

Fig. 6. Compositional dependences of the hardness $H(1)$ and electrical conductivity $\sigma(2)$ for $\mathrm{Cu}_{6} \mathrm{PS}_{5} \mathrm{I}$-based thin films. 
In this case, the film would consist of rigid nanocrystallites and their clusters distributed in more ductile amorphous matrix [26]. Hardness may increase due to this nanocomposite structure if the content of soft matrix phase is sufficiently small. However, no such effect was observed in Fig. 6. Apparently, plastic deformation during indentation occurred by the displacement of rigid clusters in the soft matrix and therefore, the hardness of the film seems to be determined by the stiffness of the matrix without the influence of nanocrystals.

\section{Conclusions}

The hardness and indentation modulus of $\mathrm{Cu}_{6} \mathrm{PS}_{5} \mathrm{I}$ crystals and thin films based on them were determined by nanoindentation exhibited significant changes with the increase of indentation depth. Deformation behavior in $\mathrm{Cu}_{6} \mathrm{PS}_{5} \mathrm{I}$ crystals at small depths $(<150 \mathrm{~nm})$ can be explained by a dislocation mechanism and the hardness changes at larger indentation depths changes in accord with the deformation gradient model. The corresponding dependences of the hardness for $\mathrm{Cu}_{6} \mathrm{PS}_{5} \mathrm{I}$-based thin films were explained using the model of soft thin film on a rigid substrate. The hardness of a thin films based on $\mathrm{Cu}_{6} \mathrm{PS}_{5} \mathrm{I}$ decreased, and conductivity increased with the increase of copper concentration. These effects can be attributed to spinodal decomposition resulting in formation of conducting clusters and dendrites in an amorphous matrix.

\section{References}

1. Kuhs W.F., Nitsche R., Scheunemann K. The argyrodites - a new family of the tetrahedrally close-packed structures. Mat. Res. Bull. 1979. 14. P. 241-248.

2. Studenyak I.P., Kranjčec M., Kovacs Gy.Sh., Panko V.V., Mitrovcij V.V., Mikajlo O.A. Structural disordering studies in $\mathrm{Cu}_{6+\delta} \mathrm{PS}_{5} \mathrm{I}$ single crystals. Mater. Sci. Eng. 2003. B 97. P. 34-38.

3. Gagor A., Pietraszko A., Kaynts D. Diffusion paths formation for $\mathrm{Cu}^{+}$ions in superionic $\mathrm{Cu}_{6} \mathrm{PS}_{5} \mathrm{I}$ single crystals studied in terms of structural phase transition. J. Solid State Chem. 2005. 178. P. 33663375.

4. Studenyak I.P., Stefanovich V.O., Kranjčec M., Desnica D.I., Azhnyuk Yu.M., Kovacs Gy.Sh., Panko V.V. Raman scattering studies of $\mathrm{Cu}_{6} \mathrm{PS}_{5} \mathrm{Hal}$ $(\mathrm{Hal}=\mathrm{Cl}, \mathrm{Br}$ and I) fast-ion conductors. Solid State Ionics. 1997. 95. P. 221-225.

5. Samulionis V., Banys J., Vysochanskii Y., Studenyak I. Investigation of ultrasonic and acoustoelectric properties of ferroelectricsemiconductor crystals. Ferroelectrics. 2006. 336. P. 29-38.

6. Studenyak I.P., Kranjčec M., Kurik M. Urbach rule and disordering processes in $\mathrm{Cu}_{6} \mathrm{P}\left(\mathrm{S}_{1-\mathrm{x}} \mathrm{Se}_{\mathrm{x}}\right)_{5} \mathrm{Br}_{1-\mathrm{y}} \mathrm{I}_{\mathrm{y}}$ superionic conductors. J. Phys. Chem. Solids. 2006. 67. P. 807-817.

7. Studenyak I.P., Kranjčec M., Kovacs Gy.Sh., Desnica I.D., Panko V.V., Slivka V.Yu. Influence of compositional disorder on optical absorption processes in $\mathrm{Cu}_{6} \mathrm{P}\left(\mathrm{S}_{1-\mathrm{x}} \mathrm{Se}_{\mathrm{x}}\right)_{5} \mathrm{I}$ crystals. J. Mater. Res. 2001. 16. P. 1600-1608.

8. Studenyak I.P., Kranjčec M., Kovacs Gy.S., Desnica-Franković I.D., Panko V.V., Guranich P.P. Electric conductivity and optical absorption edge of $\mathrm{Cu}_{6} \mathrm{P}\left(\mathrm{Se}_{\mathrm{x}} \mathrm{S}_{1-\mathrm{x}}\right)_{5} \mathrm{I}$ fast-ion conductors in the seleniumrich region. J. Phys. Chem. Solids. 2001. 62. P. 665-672.

9. Kranjčec M., Studenyak I.P., Bilanchuk V.V., Dyordyaj V.S., Panko V.V. Compositional behaviour of Urbach absorption edge and excitonphonon interaction parameters in $\mathrm{Cu}_{6} \mathrm{PS}_{5} \mathrm{I}_{1-\mathrm{x}} \mathrm{Br}_{\mathrm{x}}$ superionic mixed crystals. J. Phys. Chem. Solids. 2004. 65. P. 1015-1020.

10. I. Golovin Yu.I. Nanoindentation and mechanical properties of solids in submicrovolumes, thin nearsurface layers and films: A review. Physics of Solid State. 2008. 50. P. 2205-2236.

11. Li X., Bhushan B. A review of nanoindentation continuous stiffness measurement technique and its applications. Materials Characterization. 2002. 48. P. 11-36.

12. Milman Yu.V., Golubenko A.A., Dub S.N. Indentation size effect in nanohardness. Acta Materialia. 2002. 59. P. 7480-7487.

13. Giannakopoulos A.E., Suresh S. Determination of elastoplastic properties by instrumented sharp indentation. Scripta Mater. 1999. 40. P. 1191-1198.

14. Golovin Yu.I. Nanoindentation and Its Capabilities. Moscow, Mashinostroenie, 2009 (in Russian).

15. Mason J.K., Lund A.C., Schuh C.A. Determining the activation energy and volume for the onset of plasticity during nanoindentation. Phys. Rev. B. 2006. 73. P. 054102:1-14.

16. Ashby M.F. The deformation of plastically nonhomogeneous materials. Phil. Mag. 1970. 21. P. 399-424.

17. Gao H., Huang Y., Nix W.D. Hutchinson J.W. Mechanism based strain gradient plasticity - I. Theory. J. Mech. Phys. Solids. 1999. 47. P. 12391263.

18. Nix W.D., Gao H. Indentation size effects in crystalline materials: A law for strain gradient plasticity. J. Mech. Phys. Solids. 1998. 46. P. 411425.

19. Matthew R., Begley J., Hutchinson W. The mechanics of size-dependent indentation. J. Mech. Phys. Solids. 1998. 46. P. 2049-2068.

20. Zong Z., Lou J., Adewoye O.O., Elmustafa A.A., Hammad F., Soboyejo W.O. Indentation size effects in the nano and microhardness of FCC single crystal metals. Materials and Manufacturing Processes. 2007. 22. P. 228-237. 
21. Lofaj F., Nemeth D. The effects of tip sharpness and coating thickness on nanoindentation measurements in hard coatings on softer substrates by FEM. Thin Solid Films. 2017. 644. P. 173-181.

22. Tsui T.Y., Pharr G.M. Substrate effects on nanoindentation mechanical property measurement of soft films on hard substrates. J. Mater. Res. 1999. 14. P. 292-301.

23. Bilanych V.S., Lofaj F., Flachbart K., Csach K., Kuzma V.V., Rizak V.M. Nanoindentation of amorphous films of the Ge-As-Se system. Physics of Solid State. 2014. 56. P. 1163-1167.

24. Studenyak I., Rybak S., Bendak A., Izai V., Guranich P., Kúš P., Mikula M. Structural disordering studies of $\mathrm{Cu}_{6} \mathrm{PS}_{5} \mathrm{I}$-based thin films deposited by magnetron sputtering. EPJ Web of Conferences. 2017. 133. P. 02002:1-3.

25. Studenyak I.P., Bendak A.V., Izai V.Yu., Guranich P.P., Kúš P., Mikula M., Grančič B., Zahoran M., Greguš J., Vincze A., Roch T., Plecenik T. Electrical and optical parameters of $\mathrm{Cu}_{6} \mathrm{PS}_{5} \mathrm{I}$-based thin films deposited using magnetron sputtering. Semiconductor Physics, Quantum Electronics \& Optoelectronics. 2016. 19. P. 79-83.

26. Studenyak I.P., Izai V.Yu., Bendak A.V., Guranich P.P., Azhniuk Yu.M., Kúš P., Zahn D.R.T. Optical and electrical properties of $\mathrm{Cu}_{6} \mathrm{PS}_{5} \mathrm{I}$-based thin films versus copper content variation. Ukr. J. Phys. Opt. 2017. 18. P. 232-238.

\section{Authors and CV}

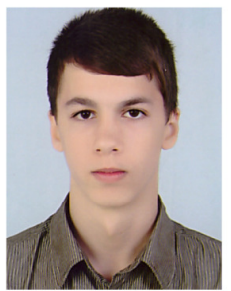

Vasyl V. Bilanych, born in 1996. This time, he studies at the magistracy of Uzhhorod National University at the Faculty of Physics. Authored 2 publications. The area of his scientific interests includes relaxation phenomena in chalcogenide materials.

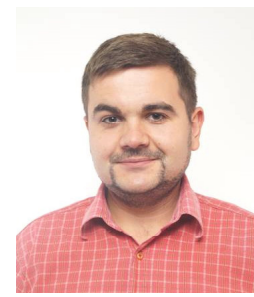

Andrii V. Bendak, born in 1992. Researcher at the Applied Physics Department of Uzhhorod National University, Ukraine. Authored 14 publications and 4 patents. The area of his scientific interests includes physical properties of superionic conductors.

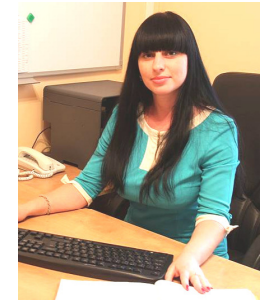

Kateryna V. Skubenych, born in 1985. She has completed post graduate studies. Head of the department of Patent and Licensing Providing and Commercialization of the Intellectual Property Objects at Uzhhorod National University. Authored 5 publications. The area of her scientific interests includes relaxation phenomena in chalcogenide materials.

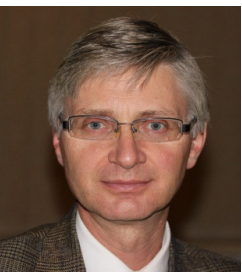

František Lofaj, Assoc. Prof. RNDr. DrSc., Head of department of structural ceramics, Institute of materials research, Kosice, Slovakia. Scientific activities: PVD deposition technologies for hard coatings, nanoindentation and tribology of PVD coatings, electron microscopy of ceramic materials, atomic force microscopy, development of the methods for testing mechanical properties of brittle materials.

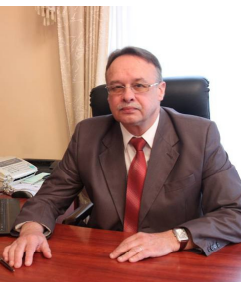

Ihor P. Studenyak, born in 1960, defended his Dr. Sc. degree in Physics and Mathematics in 2003 and became full professor in 2004. Vice-rector for scientific work at Uzhhorod National University, Ukraine. Authored over 200 publications, 120 patents, 15 textbooks. The area of his scientific interests includes physical properties of semiconductors, ferroics and superionic conductors.

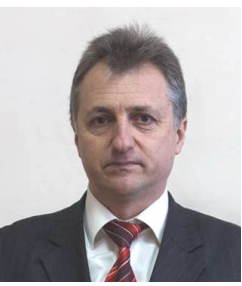

Vitaliy S. Bilanych, born in 1963 , defended his $\mathrm{PhD}$ thesis in Physics and Mathematics in 1993. Became associate professor in 2003 and works at the Applied Physics Department of Uzhhorod National University. Authored over 80 publications. The area of his scientific interests includes physical properties of non-crystalline semiconductors, relaxation phenomena in chalcogenide materials.

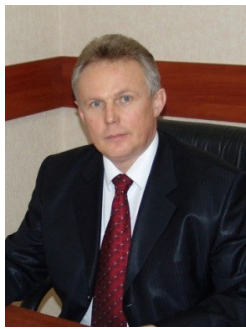

Vasyl M. Rizak, Doctor of Physical and Mathematical Sciences, Professor, Head of Department of solid-state electronics, information security head of the Transcarpathian branch of the Ukrainian Physical Society. The area of scientific interests is solid state physics. 